\title{
Emission from Charge Recombination between Radical Cations and Radical Anions of 9-Cyano-10-( $p$-substituted phenyl)anthracene Generated during Pulse Radiolysis
}

\author{
Shingo Samori, ${ }^{a}$ Sachiko Tojo, ${ }^{a}$ Mamoru Fujitsuka, ${ }^{a}$ Jui-Hsien Lin ( 林瑞莤 ), \\ Tong-Ing Ho ( 何東英), ${ }^{\mathrm{b}}$ Jye-Shane Yang ${ }^{\mathrm{b}}$ ( 楊吉水) and Tetsuro Majima ${ }^{\mathrm{a}}$ * \\ ${ }^{a}$ The Institute of Scientific and Industrial Research (SANKEN), Osaka University, Mihogaoka 8-1, \\ Ibaraki, Osaka 567-0047, Japan \\ ${ }^{\mathrm{b}}$ Department of Chemistry, National Taiwan University, Taipei 10617, Taiwan, R.O.C.
}

\begin{abstract}
Emission from charge recombination between radical cations and anions of 9-cyano-10-( $p$-substituted phenyl)anthracenes (RA, where $\mathrm{R}$ is 10 - $p$-substituted phenyl: $\mathrm{R}=$ Phenyl (PA), anisyl (OA), $p$ - $N, N$-dimethylaminophenyl (NA), $N, N$-di- $p$-anisylaminophenyl (DA)), as donor-acceptor type molecules, generated during the pulse radiolysis in benzene was measured together with the transient absorption of RA radical cations $\left(\mathrm{RA}^{\circ+}\right)$ and anions $\left(\mathrm{RA}^{-}\right)$. Based on the transient absorption and density functional theory (DFT-B3LYP/6-31G*) calculation, a twisted geometry is assumed for all RA in the ground state, $\mathrm{RA}^{\bullet+}$, and $\mathrm{RA}^{\bullet-}$. It is suggested that the positive charge of $\mathrm{PA}^{\bullet+}, \mathrm{OA}^{\bullet+}$, and $\mathrm{NA}^{\bullet+}$ is delocalized on two moieties, and that of $\mathrm{DA}^{\circ+}$ is localized on the donor $N, N$-di-p-anisylaminophenyl moiety, while the negative charge of all $\mathrm{RA}^{\bullet-}$ is mainly on the acceptor 9-(10-cyano)anthracenyl moiety. When both RA ${ }^{*+}$ and $\mathrm{RA}^{--}$are generated with sufficiently high concentrations during the pulse radiolysis in benzene, the charge recombination between $\mathrm{RA}^{\circ+}$ and $\mathrm{RA}^{\bullet-}$ occurred to give RA in the singlet excited state $\left({ }^{1} \mathrm{RA}^{*}\right)$ as the emissive species, but not the excimers because of the twisted geometries of $\mathrm{RA}^{{ }^{\circ+}}$ and $\mathrm{RA}^{{ }^{-0}}$ with the large torsional angles between the 9-(10-cyano)anthracenyl and $p$-substituted phenyl moieties. Not only the fluorescence quantum yield of ${ }^{1} \mathrm{RA}^{*}$ but also the energy differences between the annihilation enthalpy change and the excitation energy of ${ }^{1} \mathrm{RA}^{*}$ are important factors for the radiolysis induced emission intensity of RA in benzene.
\end{abstract}

Keywords: Radical cation; Radical anion; Charge recombination; Pulse radiolysis; DFT calculation.

\section{INTRODUCTION}

Recently, organic $\pi$-conjugated donor-acceptor type molecules have attracted considerable attention as electroluminescent materials for OLEDs. ${ }^{1}$ Electrogenerated chemiluminescence (ECL) from donor-acceptor type molecules can originate from the locally excited states of the donor or acceptor moiety, the intramolecular charge transfer (ICT) states, ${ }^{2,3,4 a-c}$ or even from intermolecular excimers or exciplexes. ${ }^{2,3,4 d-\mathrm{e}}$ Most of luminescent donor-acceptor type molecules are emissive in their dilute solutions, while they are weakly emissive in concentrated solutions or in thin films, because they aggregate to form less emissive species such as excimers, leading to considerable decreasing of the luminescence efficiency. It is obvious that molecular structure-property relationships for donor-acceptor type molecules provide us valuable information for the design of donor-acceptor type molecules with an efficient luminescence character.

Structure-property relationships for biphenyl type compounds have been subjected to study for years. ${ }^{5,6}$ The balance between $\pi$-electron conjugation (which favors the planar structure) and repulsion between ortho hydrogen atoms (which favors the twisted conformer) causes biphenyl to have a nonplanar and twisted structure. When an electron is removed from or added to biphenyl type compounds,

Dedicated to the memory of the late Professor Ho Tong-Ing.

* Corresponding author. Tel: Japan+6-6879-8495; Fax: +6-6879-8499; E-mail: majima@sanken.osaka-u.ac.jp 
$\pi$-electron conjugation induces a change in the torsional angle between the two phenyl rings. ${ }^{6}$ Planar or nearly planar structures have also been suggested for non-substituted biphenyl radical cations and anions in solution. The structural changes of substituted biphenyls such as chlorobiphenyls induced by one-electron oxidation and reduction have also been investigated by time-resolved resonance Raman spectroscopy and density functional theory (DFT) calculations. ${ }^{7}$ The structures (torsional angle and bond length) of polyhalogenated biphenyl radical cations and anions are affected by the substitution position mainly due to the steric interactions.

9-Phenylanthracene has a torsional angle between 9-anthracenyl and phenyl moieties, and it is modified to several derivatives with donor-acceptor character by introducing donor and acceptor substituents on 9-anthracenyl and phenyl groups. ${ }^{3}$ In this paper, we report spectral properties of 9-cyano-10-( $p$-substituted phenyl)anthracenes where the phenyl group has an electron donating substituent on $p$-position (RA, where $\mathrm{R}$ is 10-p-substituted phenyl: $\mathrm{R}=$ Phenyl (PA), anisyl (OA), $p$ - $N, N$-dimethylaminophenyl (NA), $N, N$-di- $p$-anisylaminophenyl (DA)), and radical cations and anions of RA (RA ${ }^{\bullet+}$ and $\mathrm{RA}^{\bullet-}$, respectively), with a particular focus on the emission behavior originating from the charge recombination of $\mathrm{RA}^{\bullet+}$ and $\mathrm{RA}^{{ }^{\circ-}}$. The selective formation of RA ${ }^{\bullet+}$ and $\mathrm{RA}^{{ }^{--}}$was performed to clarify the properties during the pulse radiolysis in 1,2-dichloroethane (DCE) and dimethylformamide (DMF), respectively. The torsional angles $(\psi)$ between the 9-(10-cyano)anthracenyl and $p$-substituted phenyl moieties and the spin density distributions of $\mathrm{RA}^{{ }^{*+}}$ and $\mathrm{RA}^{{ }^{--}}$ were calculated from the DFT calculation.

In our previous papers, we proposed the emission mechanisms of donor-acceptor type molecules with an ethynyl linkage (DEA) such as phenylquinolinylethynes, ${ }^{8 \mathrm{a}}$ phenyl(9-acridinyl)ethynes, ${ }^{8 \mathrm{~b}}$ phenyl(9-cyanoanthracenyl)ethynes, ${ }^{8 \mathrm{~b}}$ and arylethynylpyrenes ${ }^{8 \mathrm{c}}$ during pulse radiolysis in benzene (Bz). Based on the transient absorption and emission measurements and the steady-state spectral measurements, the formation of DEA in the singlet excited state $\left({ }^{1} \mathrm{DEA}^{*}\right)$ and/or singlet excimer $\left({ }^{1} \mathrm{DEA}_{2}{ }^{*}\right)$ results from the charge recombination between the DEA radical cation and anion $\left(\mathrm{DEA}^{\circ+}\right.$ and $\mathrm{DEA}^{\circ}{ }^{-}$, respectively) which are generated initially from the radiolytic reaction in Bz. The results of RA are compared with those of DEA at the focus of the emission from the charge recombination.

\section{EXPERIMENTAL SECTION}

\section{Measurements of Steady-state Spectral Properties}

UV Spectra were recorded in Bz with a Shimadzu UV-3100PC UV/visible spectrometer using a transparent rectangular cell made from quartz $(1.0 \times 1.0 \times 4.0 \mathrm{~cm}$, path length of $1.0 \mathrm{~cm}$ ). Fluorescence spectra were measured by a Hitachi 850 spectrofluorometer. The fluorescence quantum yields $\left(\phi_{\mathrm{fl}}\right)$ were determined by using 9,10-diphenylanthracene $^{9 \mathrm{a}}\left(\phi_{\mathrm{fl}}=0.90\right.$ in cyclohexane, $\left.\lambda_{\mathrm{ex}}=360 \mathrm{~nm}\right)$ and coumarin $334^{9 \mathrm{~b}}\left(\phi_{\mathrm{fl}}=0.69\right.$ in methanol, $\left.\lambda_{\mathrm{ex}}=400 \mathrm{~nm}\right)$ standards.

\section{Pulse Radiolysis}

Pulse radiolysis experiments were performed using an electron pulse ( $28 \mathrm{MeV}, 8 \mathrm{~ns}, 0.87 \mathrm{kGy}$ per pulse) from a linear accelerator at Osaka University. All the sample solutions were prepared in a $1-10 \mathrm{mM}$ concentration in $\mathrm{Bz}$ in a rectangular quartz cell $(0.5 \times 1.0 \times 4.0 \mathrm{~cm}$, path length of $1.0 \mathrm{~cm}$ ). These solutions were saturated with Ar gas by bubbling with it for $10 \mathrm{~min}$ at room temperature before irradiation. The kinetic measurements were performed using a nanosecond photoreaction analyzer system (Unisoku, TSP-1000). The monitor light was obtained from a pulsed 450-W Xe arc lamp (Ushio, UXL-451-0), which was operated by a large current pulsed-power supply that was synchronized with the electron pulse. The monitor light was passed through an iris with a diameter of $0.2 \mathrm{~cm}$ and sent into the sample solution at a perpendicular intersection to the electron pulse. The monitor light passing through the sample was focused on the entrance slit of a monochromator (Unisoku, MD200) and detected with a photomultiplier tube (Hamamatsu Photonics, R2949). The transient absorption and emission spectra were measured using a photodiode array (Hamamatsu Photonics, S3904-1024F) with a gated image intensifier (Hamamatsu Photonics, C2925$01)$ as a detector. To avoid pyrolysis of the sample solution by monitor light, a suitable cutoff filter was used.

\section{RESULTS AND DISCUSSION}

\section{Steady-state Spectral Properties of RA}

Scheme I depicts the chemical structures of donoracceptor type molecules having 9-(10-cyano)anthracenyl moiety (RA = PA, OA, NA, and DA). The electron-donat- 
Scheme I Chemical structures of 9-cyano-10-( $p$-substituted phenyl)anthracenes with a substituent on the phenyl moiety (RA) used in this study<smiles>N#Cc1c2ccccc2c(-c2ccccc2)c2ccccc12</smiles>

PA<smiles>COc1ccc(-c2c3ccccc3c(C#N)c3ccccc23)cc1</smiles>

OA<smiles>CN(C)c1ccc(-c2c3ccccc3c(C#N)c3ccccc23)cc1</smiles>

NA<smiles>COc1ccc(N(c2ccc(OC)cc2)c2ccc(-c3c4ccccc4c(C#N)c4ccccc34)cc2)cc1</smiles>

DA ing character of the substituents increases in the order of phenyl $<p$-anisyl $<p$ - $N, N$-(dimethylamino)phenyl $<$ and $N, N$-di- $p$-anisylaminophenyl groups. ${ }^{3}$ Spectral properties of RA in $\mathrm{Bz}(\varepsilon=2.28)$, cyclohexane ( $\varepsilon=2.02), \mathrm{CH}_{2} \mathrm{Cl}_{2}(\varepsilon=$ 9.08), and $\mathrm{CH}_{3} \mathrm{CN}(\varepsilon=37.5)$ are listed in Table 1. The ground-state absorption peaks of RA in Bz are shown in Table 1 to have little dependence on the solvent polarity. It can be seen in Fig. 1(a) that, for NA and DA having stronger donor substituents, the absorption spectrum shifts to the longer wavelength side up to $500 \mathrm{~nm}$ and changes to have a structureless feature. This red shift can be attributed to the charge-transfer (CT) excited state. A little change of fluorescence spectra depending on the solvent was observed for PA and OA (Fig. 1(b)). On the other hand, the fluorescence spectra of NA and DA were dramatically affected by the solvent polarity (Fig. 1(b)). Fluorescence spectra of NA and DA in several solvents have been reported to show two fluorescence maxima around $440 \mathrm{~nm}$ (so-called B band) and 480-600 nm (A band), ${ }^{3}$ which can be well understood by assuming two electronic excited states, a very polar and less polar excited states, A and B, respectively. ${ }^{10}$ This observation of dual fluorescence may be attributable to the existence of twisted intramolecular CT (TICT) excited states. However, the fluorescence spectra of NA in $\mathrm{CH}_{2} \mathrm{Cl}_{2}$, and $\mathrm{NA}$ and DA in $\mathrm{CH}_{3} \mathrm{CN}$ showed a very weak $\mathrm{B}$ band but no $\mathrm{A}$ band. The $\phi_{\mathrm{fl}}$ values of $\mathrm{NA}$ in $\mathrm{CH}_{2} \mathrm{Cl}_{2}$, and $\mathrm{NA}$ and DA in $\mathrm{CH}_{3} \mathrm{CN}$ were estimated to be $0.062,0.045$, and 0.026 , respectively. Compared to $\phi_{\mathrm{fl}}$ values of NA and DA in cyclohexane $(0.12$ and 0.33 , respectively), these values were very small. For NA and DA in polar solvents, the excited state $A$ is assumed to be a very low-lying excited state. It may be explained that the fluorescence quantum yields of NA and DA in polar solvents were significantly reduced due to the increase of the internal conversion rate. The spectroscopic properties of 4-(9-anthryl)- $N, N$-dimethylaniline (ADMA) has been reported by comparison with 1-methyl-5-(9-anthryl)indole with the amino nitrogen immobilized in the planar structure. ${ }^{11}$ It is suggested that the twist around the anthryl-phenyl C-C bond is important for the spectroscopic properties depending on the polarity of

Table 1. Steady-state spectral properties of RA in $\mathrm{Bz}$, cyclohexane, $\mathrm{CH}_{2} \mathrm{Cl}_{2}$, and $\mathrm{CH}_{3} \mathrm{CN}^{\mathrm{a}}$

\begin{tabular}{|c|c|c|c|c|c|c|c|c|c|c|c|c|c|}
\hline \multirow[t]{2}{*}{ RA } & $\begin{array}{c}\lambda_{\max }^{\mathrm{Abs}} \\
/ \mathrm{nm}\end{array}$ & $\begin{array}{l}\lambda_{\max }^{\mathrm{Fl}} \\
/ \mathrm{nm}\end{array}$ & $\begin{array}{c}\text { Stokes } \\
\text { shift } \\
/ \mathrm{nm}\end{array}$ & $\phi_{\mathrm{fl}}$ & $\begin{array}{l}\lambda_{\max }^{\mathrm{Fl}} \\
/ \mathrm{nm}\end{array}$ & $\begin{array}{c}\text { Stokes } \\
\text { shift } \\
/ \mathrm{nm}\end{array}$ & $\phi_{\mathrm{fl}}$ & $\begin{array}{l}\lambda_{\max }^{\mathrm{Fl}} \\
/ \mathrm{nm}\end{array}$ & $\begin{array}{c}\text { Stokes } \\
\text { shift } \\
/ \mathrm{nm} \\
\end{array}$ & $\phi_{\mathrm{fl}}$ & $\begin{array}{l}\lambda_{\max }^{\mathrm{Fl}} \\
/ \mathrm{nm}\end{array}$ & $\begin{array}{c}\text { Stokes } \\
\text { shift } \\
\text { /nm }\end{array}$ & $\phi_{\mathrm{fl}}$ \\
\hline & \multicolumn{4}{|c|}{ in $\mathrm{Bz}$} & \multicolumn{3}{|c|}{ in cyclohexane } & \multicolumn{3}{|c|}{ in $\mathrm{CH}_{2} \mathrm{Cl}_{2}$} & \multicolumn{3}{|c|}{ in $\mathrm{CH}_{3} \mathrm{CN}$} \\
\hline PA & $389(370,412)$ & $453(433)$ & 64 & 0.37 & $444(424)$ & 57 & 0.45 & $458(438)$ & 68 & 0.38 & 456 & 66 & 0.30 \\
\hline $\mathrm{OA}$ & $392(370,413)$ & 465 (449) & 73 & 0.11 & $428(455)$ & 40 & 0.19 & 464 & 71 & 0.091 & 467 & 76 & 0.043 \\
\hline NA & $414(370,394)$ & $524(440)$ & 110 & 0.23 & $466(430)$ & 57 & 0.12 & $588(448)$ & 179 & 0.24 & 443 & 34 & 0.045 \\
\hline DA & $411(370,393)$ & $558(440)$ & 147 & 0.35 & 493 & 88 & 0.33 & 457 & 45 & 0.062 & 455 & 46 & 0.026 \\
\hline
\end{tabular}

${ }^{\mathrm{a}}$ Fluorescence quantum yield $\left(\phi_{\mathrm{fl}}\right)$ values for $\mathrm{RA}$ in $\mathrm{Bz}$, cyclohexane, $\mathrm{CH}_{2} \mathrm{Cl}_{2}$, and $\mathrm{CH}_{3} \mathrm{CN}$ were redetermined in this study because of mistakes in the previous $\phi_{\mathrm{fl}}$ measurement (ref. 3). The values in parenthesis are the maxima of vibrational peaks. 
solvents, but not the rotation of the amino group. This is consistent with the properties of NA and DA.

\section{Geometries of $\mathbf{R A}, \mathrm{RA}^{\bullet+}$, and $\mathrm{RA}^{\bullet}$}

The observation of the electronic properties can be better understood by analyzing the results obtained from density functional calculations using Becke's three parameter set with Lee-Yang-Parr modification (B3LYP) with the $6-31 \mathrm{G}^{*}$ basis set of theory. ${ }^{12}$ It is of interest to us to investigate the nature of the charged molecules by the DFT calculations in an attempt to gain maximum insight into their electronic structure. Fig. 2 shows the spin density maps of 9-cyanoanthracene radical cation $\left(9 \mathrm{CA}^{\bullet+}\right)$, 9-cyanoanthracene radical anion $\left(9 \mathrm{CA}^{\bullet-}\right), \mathrm{RA}^{\bullet+}$, and $\mathrm{RA}^{\bullet-}$. It is indicated that the positive charge of $\mathrm{RA}^{\bullet+}$ except for $\mathrm{DA}^{\bullet+}$ is delocalized on two aromatic moieties, while the negative charge of $\mathrm{RA}^{\bullet-}$ is mainly on 9-(10-cyano)anthracenyl moiety. In the case of $\mathrm{DA}^{\bullet+}$, the positive charge is localized mainly on the donor moiety, $N, N$-di- $p$-anisylaminophenyl group. Twisted geometries are assumed for all $\mathrm{RA}^{\bullet+}$ and $\mathrm{RA}^{\bullet-}$, together with neutral RA, which have the torsional angle $(\psi)$ between 9-(10-cyano)anthracenyl and $p$-substituted phenyl moieties as summarized in Table 2. It is clearly shown that all $\mathrm{RA}^{\bullet+}$ and $\mathrm{RA}^{\bullet-}$ have a twisted geometry although $\psi$ value becomes smaller than neutral RA. Compared to biphenyl, larger repulsion is assumed for 9-cyano-10-phenylanthracenes with a substituent due to the presence of the bulky 9-(10-cyano)anthracenyl moiety. Therefore, twisted geometries are adequately taken for
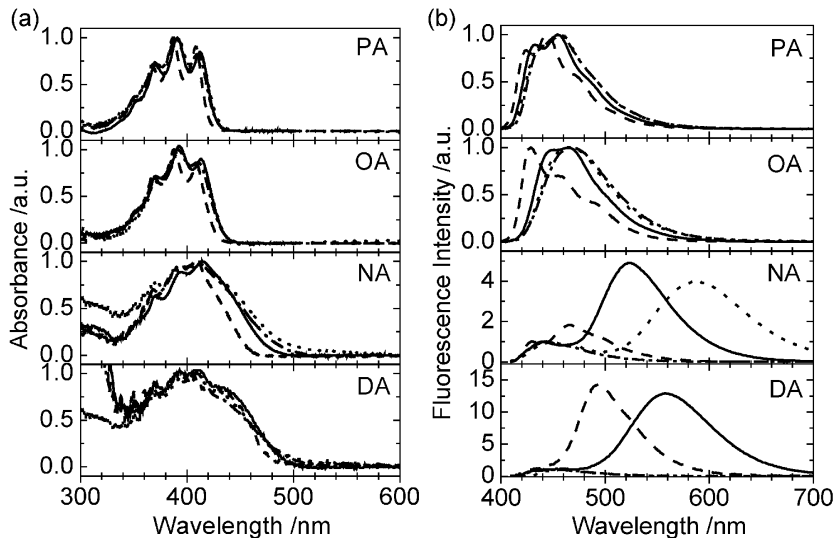

Fig. 1. Absorption (a) and fluorescence spectra (b) observed by the steady-state measurement of RA in Ar-saturated $\mathrm{Bz}$ (solid line), cyclohexane (broken line), $\mathrm{CH}_{2} \mathrm{Cl}_{2}$ (dotted line) and $\mathrm{CH}_{3} \mathrm{CN}$ (dashed-dotted line). All solutions were prepared at a dilute concentration $\left(10^{-5} \mathrm{M}\right)$.
$\mathrm{RA}^{\circ+}$ and $\mathrm{RA}^{\bullet-}$.

\section{Transient Absorption Spectra of $\mathbf{R A}^{\text {o+ }}$}

It is well established that a radical cation of solute molecule is generated during the pulse radiolysis in 1,2dichloroethane (DCE). ${ }^{13}$ Fig. 3 shows the transient absorption spectra observed during the pulse radiolysis of 9CA and RA in Ar-saturated DCE. The absorption spectra observed for 9CA and RA with a half lifetime of micro second order can be assigned to $9 \mathrm{CA}^{\bullet+}$ and $\mathrm{RA}^{\bullet+}$, respectively. Compared to $9 \mathrm{CA}^{\bullet+}, \mathrm{PA}^{\bullet+}$, and $\mathrm{OA}^{\bullet+}, \mathrm{NA}^{\bullet+}$ and $\mathrm{DA}^{\bullet+}$ showed the weak absorption spectra because of low concentrations of the NA and DA solutions in DCE (approximately $1 \mathrm{mM}$ ). Since the absorption spectrum of $9 \mathrm{CA}^{\bullet+}$ with two bands around 400-500 and 700-800 nm are different from those of $\mathrm{RA}^{\bullet+}$, the electronic property of the donor

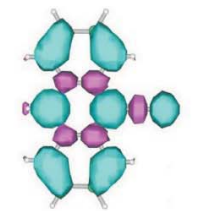

$9 \mathrm{CA}^{*+}$
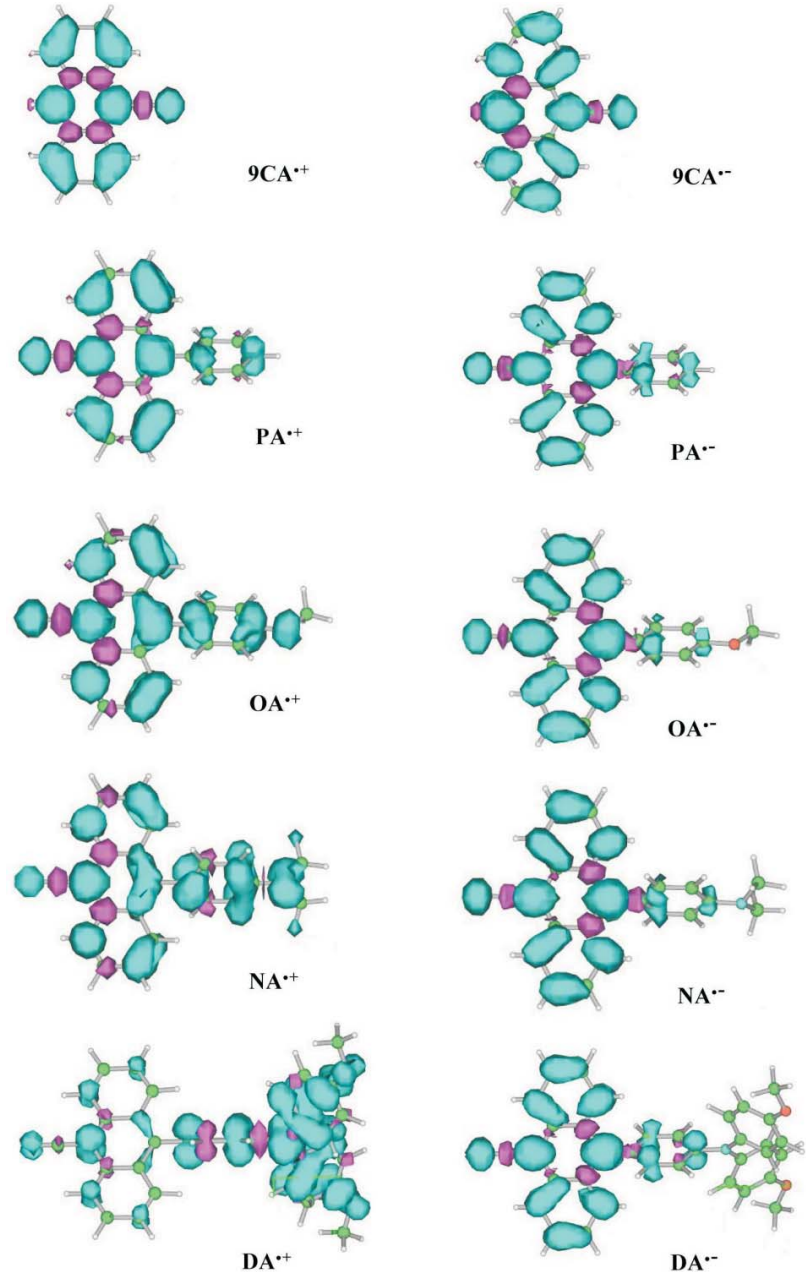

DA*- $^{--}$

Fig. 2. Spin density maps of $9 \mathrm{CA}^{\bullet+}, 9 \mathrm{CA}^{\bullet-}, \mathrm{RA}^{\bullet+}$, and $\mathrm{RA}^{\bullet-}$ obtained by the DFT (B3LYP/6-31G*) calculation. 
Table 2. Torsional angles $(\psi)$ between the two phenyl rings of neutral molecules, radical cations, and radical anions of biphenyl and RA obtained by the DFT calculation

\begin{tabular}{lccc}
\hline Molecule & Neutral & Radical cation & Radical anion \\
\hline Biphenyl & $40.5^{\mathrm{a}}, 40.1^{\mathrm{b}}$ & $19.0^{\mathrm{a}}, 18.9^{\mathrm{b}}$ & $6.3^{\mathrm{a}}, 0.0^{\mathrm{b}}$ \\
PA & 90.0 & 58.4 & 61.5 \\
OA & 73.2 & 52.5 & 64.5 \\
NA & 69.7 & 50.9 & 64.2 \\
DA & 70.8 & 61.4 & 58.7 \\
\hline
\end{tabular}

${ }^{a}$ Taken from ref. 6e (B3LYP/6-311G(d,p)). ${ }^{\mathrm{b}}$ Taken from ref. $6 \mathrm{f}$ (B3LYP/6-311+G(2d,2p)).

moiety affects the transient absorption of $\mathrm{RA}^{\bullet+}$, in which the positive charge is not localized on 9-(10-cyano)anthracenyl moiety.

Radical cations of biphenyl and 4,4'-dimethylbiphenyl have two absorption bands around 360-400 and 650-750 nm, while the 2,2'-dimethylbiphenyl radical cation has two bands around $330-380$ and $750-900 \mathrm{~nm} .{ }^{14}$ It is assumed that the nearly planar structure of biphenyl and 4,4'-dimethylbiphenyl radical cations induces charge delocalization, while the twisted geometry of 2,2'-dimethylbiphenyl radical cation causes positive charge localization. Similarly, the spectral shape of $\mathrm{RA}^{\bullet+}$ could depend on the structure. However, all $\mathrm{RA}^{\bullet+}$ have twisted geometries with the large $\psi$ values between the 9-(10-cyano)anthracenyl and $p$-sub-

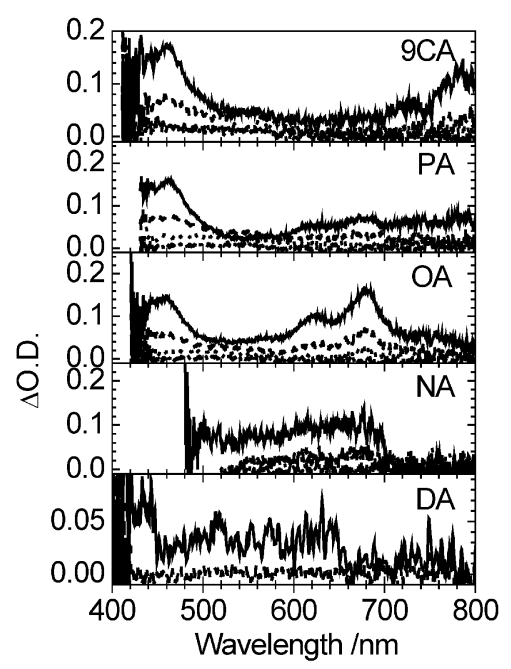

Fig. 3. Time-resolved transient absorption spectra observed at time $t=100 \mathrm{~ns}$ (solid line), 1 (broken line), 10 (dotted line), and $100 \mu$ s (dasheddotted line) after an electron pulse during the pulse radiolysis of 9CA $(5 \mathrm{mM}), \mathrm{PA}(5 \mathrm{mM})$, OA $(5 \mathrm{mM})$, NA $(1 \mathrm{mM})$, and DA $(1 \mathrm{mM})$ in Ar-saturated DCE. stituted phenyl moieties, because the large repulsion between ortho-hydrogen atoms of $p$-substituted phenyl and hydrogen atoms at 1- and 8-postions of 9-(10-cyano)anthracenyl moieties of RA and $\mathrm{RA}^{\bullet+}$ exists due to the bulky 9-(10-cyano)anthracenyl. ${ }^{6}$ Consequently, the absorption spectral shape of $\mathrm{RA}^{\bullet+}$ depending on the donor moiety at the 10 position of 9-(10-cyano)anthracenyl moiety can be explained by the electronic character of the donor moiety.

Since the spin density of $\mathrm{DA}^{\bullet+}$ is localized on $N, N$ di- $p$-anisylaminophenyl moiety based on the DFT calculation as shown in Fig. 2, the absorption spectrum of $\mathrm{DA}^{\bullet+}$, observed in the range of 450-650 nm, is expected to be similar to that of the radical cation of $N, N$-di- $p$-anisylaminobenzene. It has been reported that the triphenylamine radical cation has an absorption band around 500-700 nm, ${ }^{14}$ and that many radical cations of anisole and methoxyphenyl compounds have a broad and weak absorption band around $400 \mathrm{~nm}$. Therefore, the broad absorption spectrum of $\mathrm{DA}^{\bullet+}$ in the range of $450-650 \mathrm{~nm}$ corresponds to the $N, N$-di- $p$-anisylaminobenzene radical cation.

In our previous papers, the electronic properties of the radical cation and anion of donor-acceptor type molecules with an ethynyl linkage (DEA) were reported based on the transient absorption spectra of $\mathrm{DEA}^{\bullet+}$ and $\mathrm{DEA}^{\bullet-}$. The positive charge is assumed to be localized mainly on the donor moiety of $\mathrm{DEA}^{\bullet+}$, because of the twist around the ethynyl bond of $\mathrm{DEA}^{\bullet+}$ between the donor and acceptor moieties. On the other hand, positive charge delocalization can be assumed for $\mathrm{RA}^{\bullet+}$, except for $\mathrm{DA}^{\bullet+}$. In contrast to radical cations of biphenyl and substituted biphenyls with nearly planar structures, ${ }^{6}$ a twisted geometry is preferred for all $\mathrm{RA}^{\bullet+}$ because of the bulky 9-(10-cyano)anthracenyl moiety based on the DFT calculation. The $\psi$ values for $\mathrm{PA}^{\bullet+}\left(58.4^{\circ}\right), \mathrm{OA}^{\bullet+}\left(52.5^{\circ}\right)$, and $\mathrm{DA}^{\bullet+}\left(50.9^{\circ}\right)$ were found to be slightly smaller than those for $\mathrm{DA}^{\bullet+}\left(61.4^{\circ}\right)$. The positive charge can be delocalized in spite of the twisted geometry of $\mathrm{RA}^{\bullet+}$ with $\psi=50-60^{\circ}\left(\mathrm{PA}^{\bullet+}, \mathrm{OA}^{\bullet+}\right.$, and $\left.\mathrm{NA}^{\bullet+}\right)$. On the other hand, the positive charge is considerably localized on the donor $N, N$-di- $p$-anisylaminophenyl moiety of $\mathrm{DA}^{\bullet+}$ with a slightly larger $\psi$ value (larger than $60^{\circ}$ ).

\section{Transient Absorption Spectra of $\mathbf{R A}^{\bullet}$}

It is also well established that a radical anion of solute molecule is generated during the pulse radiolysis in dimethylformamide (DMF). ${ }^{15}$ Fig. 4 shows that the transient absorption spectra, observed during the pulse radiolysis of 9CA and RA in Ar-saturated DMF, are assigned to $9 \mathrm{CA}^{\circ-}$ 
and $\mathrm{RA}^{\bullet-}$, respectively, with the half lifetimes of micro second order. Transient absorption of $\mathrm{NA}^{\bullet-}$ showed both rise and decay, which are related to the formation and decay of $\mathrm{NA}^{\bullet-}$, respectively. The formation profile corresponds to the electron attachment to NA at a low concentration, because NA was prepared at approximately $1 \mathrm{mM}$ concentration due to the poor solubility in DMF. It should be noted that all $\mathrm{RA}^{\bullet-}$ have a broad absorption band around 500-700 nm. The spin density maps of $\mathrm{RA}^{\bullet-}$, as shown in Fig. 2, indicate that the negative charge of $\mathrm{RA}^{\bullet-}$ is localized mainly on 9-(10-cyano)anthracenyl moiety. It is also suggested from the spectral shapes of $\mathrm{RA}^{\bullet-}$ that the negative charge is localized mainly on the 9-(10-cyano)anthracenyl moiety, because all $\mathrm{RA}^{\bullet-}$ and $9 \mathrm{CA}^{\bullet-}$ have similar absorption bands in the region of 500-700 $\mathrm{nm}$. It was found based on the DFT calculation that $\psi$ values for $\mathrm{PA}^{\bullet-}\left(61.5^{\circ}\right), \mathrm{OA}^{\bullet-}\left(64.5^{\circ}\right)$, and $\mathrm{NA}^{\bullet-}\left(64.2^{\circ}\right)$ are slightly larger than those for $\mathrm{DA}^{\bullet-}$ $\left(58.7^{\circ}\right)$ (Table 2$)$. The transient absorption spectrum of $\mathrm{DA}^{\bullet-}$ showed the structureless absorption spectrum which is slightly different from those of other $\mathrm{RA}^{\bullet-}$. Therefore, it is suggested that the electronic property of the 9-(10-cyano)anthracenyl moiety, where the negative charge is considerably localized, is influenced by the donor $N, N$-di- $p$ anisylaminophenyl moiety. Such electronic interaction causes the difference of the transient absorption spectrum of $\mathrm{DA}^{\bullet-}$ from those of other $\mathrm{RA}^{\bullet-}$. The spectral features of

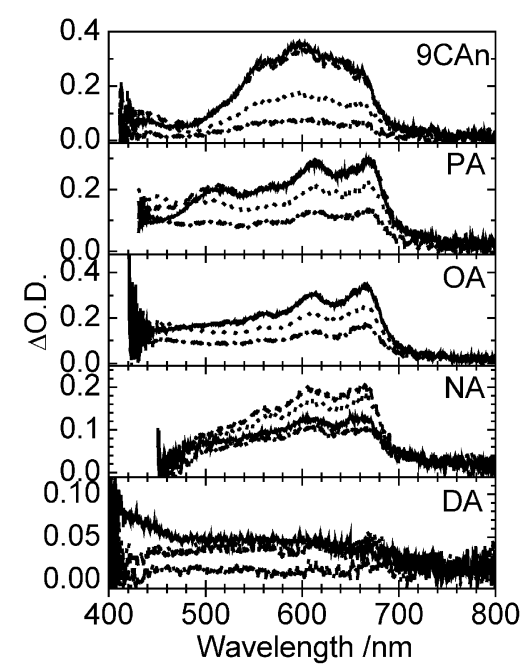

Fig. 4. Time-resolved transient absorption spectra observed at time $t=100 \mathrm{~ns}$ (solid line), 1 (broken line), 10 (dotted line), and $100 \mu$ s (dasheddotted line) after an electron pulse during the pulse radiolysis of $9 \mathrm{CA}(5 \mathrm{mM}), \mathrm{PA}(5 \mathrm{mM})$, $\mathrm{OA}(5 \mathrm{mM})$, NA $(1 \mathrm{mM})$, and DA $(1 \mathrm{mM})$ in Ar-saturated DMF.
$\mathrm{RA}^{\bullet-}$ are similar to those of $\mathrm{DEA}^{\bullet-}$ with the negative charge localized mainly on acceptor moiety and the twisted structures. ${ }^{8}$

\section{Emission Generated from Charge Recombination be- tween $\mathrm{RA}^{\bullet+}$ and $\mathrm{RA}^{\bullet-}$}

The electrochemical properties of $\mathrm{RA}$ in $\mathrm{CH}_{2} \mathrm{Cl}_{2}$ are listed in Table 3. Using a setup consisting of fluorescence spectrophotometer and voltammograph with a PC interface, electrogenerated chemiluminescence (ECL) from RA was observed with a peak at 456-538 nm in the presence of $0.05 \mathrm{M}$ tetrabutylammonium perchlorate (TBAP) as supporting electrolyte. ${ }^{3}$ In our previous papers, ${ }^{8}$ we reported the emission mechanisms of DEA during pulse radiolysis in Bz. Along with this result, we examined the emission measurement during the pulse radiolysis of RA with donor-acceptor structure in Bz.

The annihilation enthalpy change $\left(-\Delta H^{\circ}\right)$ for the charge recombination between the radical cation and anion in $\mathrm{Bz}$ is calculated by the following equation, ${ }^{8 \mathrm{c}}$

$$
-\Delta H^{\circ}=E_{\mathrm{ox}}-E_{\mathrm{red}}+0.13 \mathrm{eV}
$$

where $E_{\mathrm{ox}}$ and $E_{\mathrm{red}}$ are the oxidation and reduction potentials of RA in $\mathrm{CH}_{2} \mathrm{Cl}_{2}$. The calculated $-\Delta H^{\circ}$ values for RA are listed in Table 3. $-\Delta H^{\circ}$ for all RA are sufficiently larger than the $\mathrm{S}_{1}$-state excitation energy $\left(E_{\mathrm{S} 1}\right)$, expecting that the energy available in the charge recombination is sufficient to populate all RA in the $\mathrm{S}_{1}$ state.

Emission spectra were observed after an electron pulse during the pulse radiolysis of RA (1-10 mM) in Arsaturated $\mathrm{Bz}$. At $1 \mathrm{mM}$ concentration, all RA showed an emission peak at 460-560 $\mathrm{nm}$ during the pulse radiolysis (Fig. 5). The fluorescence maxima of NA and DA were observed at the longer wavelength side than those of PA or OA, suggesting that an emissive ICT excited state is formed for NA and DA. The radiolysis induced emission intensities of RA ( $1 \mathrm{mM}$ ) were determined from the total amount of emission as summarized in Table 4. Although the $\phi_{\mathrm{fl}}$ value of DA (0.35) was higher than those of OA (0.11) and NA (0.23) (Table 1), the radiolysis induced emission intensity of DA was the lowest (Ar: 12.9, air: 4.22). It is clear that the radiolysis induced emission intensity of RA is not proportional to the $\phi_{\mathrm{fl}}$ value. For PA, OA, NA, and DA, the energy differences between $-\Delta H^{\circ}$ and $E_{\mathrm{S} 1}\left(-\Delta H^{\circ}-E_{\mathrm{S} 1}\right)$ were estimated to be $0.75,0.47,0.49$, and $0.23 \mathrm{eV}$, respectively (Table 3$)$. The $\left(-\Delta H^{\circ}-E_{\mathrm{S} 1}\right)$ value for DA was 
Table 3. Electrochemical properties of $\mathrm{RA}$ in $\mathrm{CH}_{2} \mathrm{Cl}_{2}$, and annihilation enthalpy change $\left(-\Delta H^{\circ}\right)$ and $E_{\mathrm{S} 1}$ energies of $\mathrm{RA}$ in $\mathrm{Bz}$

\begin{tabular}{|c|c|c|c|c|c|c|c|c|}
\hline \multirow{3}{*}{ RA } & \multirow{2}{*}{$\begin{array}{c}E_{\mathrm{ox}} \\
/ \mathrm{V}\end{array}$} & \multirow{2}{*}{$\begin{array}{c}E_{\text {red }} \\
/ \mathrm{V}\end{array}$} & \multirow{2}{*}{$\begin{array}{c}-\Delta H^{\circ} \\
/ \mathrm{eV}\end{array}$} & \multicolumn{2}{|c|}{$\lambda_{\max }^{\mathrm{ECL}^{\mathrm{a}}}$} & \multirow{2}{*}{$\begin{array}{c}-\Delta H^{\circ} \\
/ \mathrm{eV}\end{array}$} & \multirow{2}{*}{$\begin{array}{l}E_{\mathrm{S} 1} \\
/ \mathrm{eV}\end{array}$} & \multirow{2}{*}{$\begin{array}{c}-\Delta H^{\circ}-E_{\mathrm{S} 1} \\
/ \mathrm{eV}\end{array}$} \\
\hline & & & & $/ \mathrm{nm}$ & $/ \mathrm{eV}$ & & & \\
\hline & \multicolumn{5}{|c|}{ in $\mathrm{CH}_{2} \mathrm{Cl}_{2}$} & \multicolumn{3}{|c|}{ in $\mathrm{Bz}$} \\
\hline PA & 1.80 & -1.55 & 3.19 & 456 & 2.72 & 3.48 & 2.73 & 0.75 \\
\hline OA & 1.48 & -1.53 & 2.85 & 480 & 2.58 & 3.14 & 2.67 & 0.47 \\
\hline NA & 1.08 & -1.58 & 2.50 & 538 & 2.30 & 2.79 & 2.37 & 0.49 \\
\hline DA & 0.86 & -1.56 & 2.26 & 535 & 2.32 & 2.55 & 2.22 & 0.23 \\
\hline
\end{tabular}

${ }^{\mathrm{a}}$ Peak wavelength and energy of the ECL.

smaller than those for other RA, suggesting that the yield of ${ }^{1} \mathrm{DA}^{*}$ is less than other ${ }^{1} \mathrm{RA}^{*}$, and that the emission intensity for DA is lower than other RA. Consequently, it is proposed that the radiolysis induced emission intensity of RA depends on both the $\phi_{\mathrm{fl}}$ and $\left(-\Delta H^{\circ}-E_{\mathrm{S} 1}\right)$ values. This was observed for RA but not for DEA, because RA showed similar $\phi_{\mathrm{fl}}$ values (0.11-0.37), but the larger variation of $\left(-\Delta H^{\circ}\right.$ $-E_{\mathrm{S} 1}$ ) values (0.23-0.75 eV). On the other hand, DEA showed the large change of $\phi_{\mathrm{fl}}$ value, but slight change of $\left(-\Delta H^{\circ}-E_{\mathrm{S} 1}\right)$ value. It should be concluded that both the $\phi_{\mathrm{fl}}$ and $\left(-\Delta H^{\circ}-E_{\mathrm{S} 1}\right)$ values are important factors of the radiolysis induced emission intensity for various donor-acceptor type compounds.

For some DEA prepared in a high concentration, the excimer emission has been observed during the pulse radiolysis in Bz. ${ }^{8}$ In order to confirm the presence or absence of excimer emission, emission spectra of RA were mea-

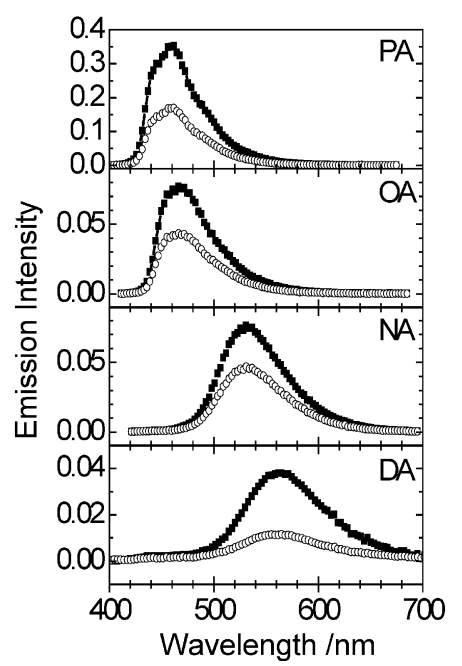

Fig. 5. Emission spectra observed during the pulse radiolysis of RA in Ar- (solid square) and airsaturated (open circle) $\mathrm{Bz}(1 \mathrm{mM})$.
Table 4. Emission maximum $\left(\lambda^{\mathrm{Em}}\right)$ and relative emission intensity during the pulse radiolysis of RA in Ar- and air-saturated $\mathrm{Bz}(1 \mathrm{mM})$

\begin{tabular}{lccc}
\hline \multirow{2}{*}{ RA } & $\lambda_{\max }^{\mathrm{Em}} / \mathrm{nm}$ & \multicolumn{2}{c}{ Relative intensity $/ \%^{\mathrm{a}}$} \\
\cline { 3 - 4 } & & in Ar-saturated Bz & in air-saturated Bz \\
\hline PA & 460 & 100 & 49.4 \\
OA & 467 & 19.8 & 10.0 \\
NA & 533 & 29.7 & 13.4 \\
DA & 560 & 12.9 & 4.22 \\
\hline
\end{tabular}

${ }^{\text {a }}$ Relative to the emission intensity for PA in Ar-saturated Bz. Emission intensity was determined from the total amount of emission.

sured at a high concentration. No excimer emission, but a monomer emission was observed during the pulse radiolysis of PA and $\mathrm{OA}$ in $\mathrm{Bz}$ at $10 \mathrm{mM}$ concentration. No experiment was examined for NA at a high concentration because of the poor solubility in Bz. The DFT calculation suggests that all $\mathrm{RA}^{\bullet+}$ and $\mathrm{RA}^{\bullet-}$ have a twisted geometry which can not allow the face-to-face interaction between $\mathrm{RA}^{\bullet+}$ and $\mathrm{RA}^{\bullet-}$ in the charge recombination, leading to the formation of the face-to-face excimer as the emissive species. The plausible mechanism of the emission during the pulse radiolysis of RA in Bz is shown in Scheme II. The difference between RA and DEA for the formation of the emissive species is also shown in Scheme III.

It should be noted that no or little emission was observed during the pulse radiolysis of RA in DCE or DMF, clearly suggesting that $\mathrm{RA}^{\bullet+}$ and $\mathrm{RA}^{\bullet-}$ itself does not emit light. In other words, both $\mathrm{RA}^{\bullet+}$ and $\mathrm{RA}^{\bullet-}$ must be formed at the same time in order to observe the emission.

Transient absorption spectra were observed during the pulse radiolysis of RA in Ar-saturated Bz (Fig. 6). The transient absorption was quenched in the presence of $\mathrm{O}_{2}$, and no transient absorption was observed in air-saturated 
Scheme II Mechanism for the emission during the pulse radiolysis of RA in Bz. The first arrow denotes the ionization process during the pulse radiolysis of $\mathrm{Bz}$

$$
\begin{aligned}
& \mathrm{Bz}-\mathrm{M} \rightarrow \mathrm{e}^{-}+\mathrm{Bz}^{\bullet+} \\
& \mathrm{Bz}^{\bullet+}+\mathrm{e}^{-} \rightarrow \mathrm{Bz}^{*} \\
& \mathrm{e}^{-}+\mathrm{RA} \rightarrow \mathrm{RA}^{\bullet-} \\
& \mathrm{Bz}^{\bullet+}+\mathrm{RA} \rightarrow \mathrm{Bz}^{\circ} \mathrm{RA}^{\bullet+} \\
& \mathrm{RA}^{\bullet-}+\mathrm{RA}^{\bullet+} \rightarrow{ }^{1} \mathrm{RA}^{*}+\mathrm{RA} \text { and }{ }^{3} \mathrm{RA}^{*}+\mathrm{RA} \\
&{ }^{3} \mathrm{Bz}^{*}+\mathrm{RA} \rightarrow \mathrm{Bz}+{ }^{3} \mathrm{RA}^{*} \\
&{ }^{3} \mathrm{RA}^{*}+{ }^{3} \mathrm{RA}^{*} \rightarrow{ }^{1} \mathrm{RA}^{*}+\mathrm{RA} \\
&{ }^{1} \mathrm{RA}^{*} \rightarrow \mathrm{RA}+h v_{\mathrm{f}}
\end{aligned}
$$

Bz. Thus, the transient absorption spectra, observed during the pulse radiolysis of RA in Ar-saturated Bz, are assigned to ${ }^{3} \mathrm{RA}^{*}$. Since no transient absorption band of $\mathrm{RA}^{\bullet+}$ and $\mathrm{RA}^{\bullet-}$ was observed immediately after an 8-ns electron pulse in $\mathrm{Bz}$, it is assumed that $\mathrm{RA}^{\bullet+}$ and $\mathrm{RA}^{\bullet-}$ immediately recombine to give ${ }^{1} \mathrm{RA}^{*}$ within a pulse duration.

The results obtained in this study indicate that the mechanism for the emission during the pulse radiolysis of $\mathrm{RA}$ in $\mathrm{Bz}$ was quite different from those of DEA. ${ }^{8} \mathrm{RA}$ showed only a monomer emission, while some DEA showed both monomer and excimer emissions. ${ }^{8 b, c}$ For DEA, it is

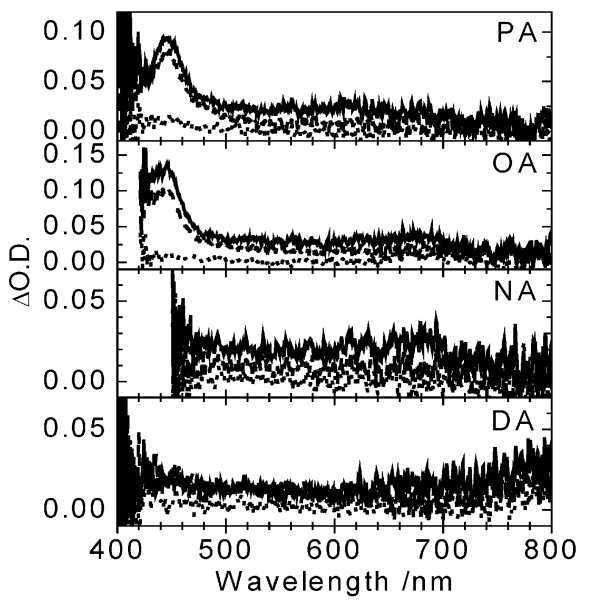

Fig. 6. Time-resolved transient absorption spectra observed at time $t=100 \mathrm{~ns}$ (solid line), $1 \mu \mathrm{s}$ (broken line), and $10 \mu$ s (dotted line) after an electron pulse during the pulse radiolysis of PA (5 $\mathrm{mM}), \mathrm{OA}(5 \mathrm{mM}), \mathrm{NA}(1 \mathrm{mM})$, and DA (1 mM) in Ar-saturated Bz. suggested that the enlargement of a $\pi$-conjugated system allows the $\pi$-stacked excimer structure due to the ethynyl bond between donor and acceptor moieties. Based on the spectral features of $\mathrm{DEA}^{\bullet+}$ and $\mathrm{DEA}^{\bullet-}$, the positive and negative charges seem to be localized on donor and acceptor moieties, respectively, leading to a twist at the ethynyl bonds of $\mathrm{DEA}^{\bullet+}$ and $\mathrm{DEA}^{\bullet-}$. Therefore, it is suggested that $\mathrm{DEA}^{\bullet+}$ and $\mathrm{DEA}^{\bullet-}$ collide neck-to-neck to generate the excimer in which two acceptor moieties are stacked in the face-to-face geometry with the donor moieties projecting away from each other due to the twisted geometry (Scheme III). On the other hand, no excimer emission was observed for RA. Since a large repulsion exists between $p$-substituted phenyl and bulky 9-(10-cyano)anthracenyl moieties without the ethynyl linker, $\pi$-stacked excimer structure can not be taken for $\mathrm{RA}^{\bullet+}$ and $\mathrm{RA}^{\bullet-}$ with the twisted structures. Therefore, it is suggested that the geometries of a radical cation and anion also affect the formation of the emissive species.

We have been reported that the radiolysis-induced emission intensity of many DEA tends to be proportional to the $\phi_{\mathrm{fl}}$ value. ${ }^{8}$ However, the results obtained during the pulse radiolysis of RA showed that the geometries of $\mathrm{RA}^{\bullet+}$ and $\mathrm{RA}^{\bullet-}$ and $\left(-\Delta H^{\circ}-E_{\mathrm{S} 1}\right)$ value, together with $\phi_{\mathrm{fl}}$ value, affect the radiolysis-induced emission intensity. In order to obtain the high emission efficiency during the pulse radiolysis, the following photophysical and electrochemical properties are important for solute molecules: (1) high $\phi_{\mathrm{fl}}$ value in solution, (2) high oxidation and reduction potentials, which correspond to large $-\Delta H^{\circ}$ values, and (3) twisted structures between donor and acceptor moieties for radical cations and anions of solute molecules to prevent the formation of the excimers with low emission intensities.

Only monomer emission was observed for all RA during pulse radiolysis in $\mathrm{Bz}$. The monomer emission was also observed for PA and OA in the ECL experiment, while the emission observed for NA and DA was not analyzed in detail (Table 3). ${ }^{3}$ Since $\mathrm{RA}^{\bullet+}$ and $\mathrm{RA}^{\bullet-}$ are generated as the initial species during both pulse radiolysis and electrochemical reaction, a similar mechanism can be assumed for the formation of emissive species. However, the results suggest that the different experimental conditions such as solvent and concentrations of $\mathrm{RA}^{\bullet+}$ and $\mathrm{RA}^{\bullet-}$ may influence the emission behaviors during the pulse radiolysis and electrochemical reaction. 


\section{Scheme III}

For PA, OA, and NA
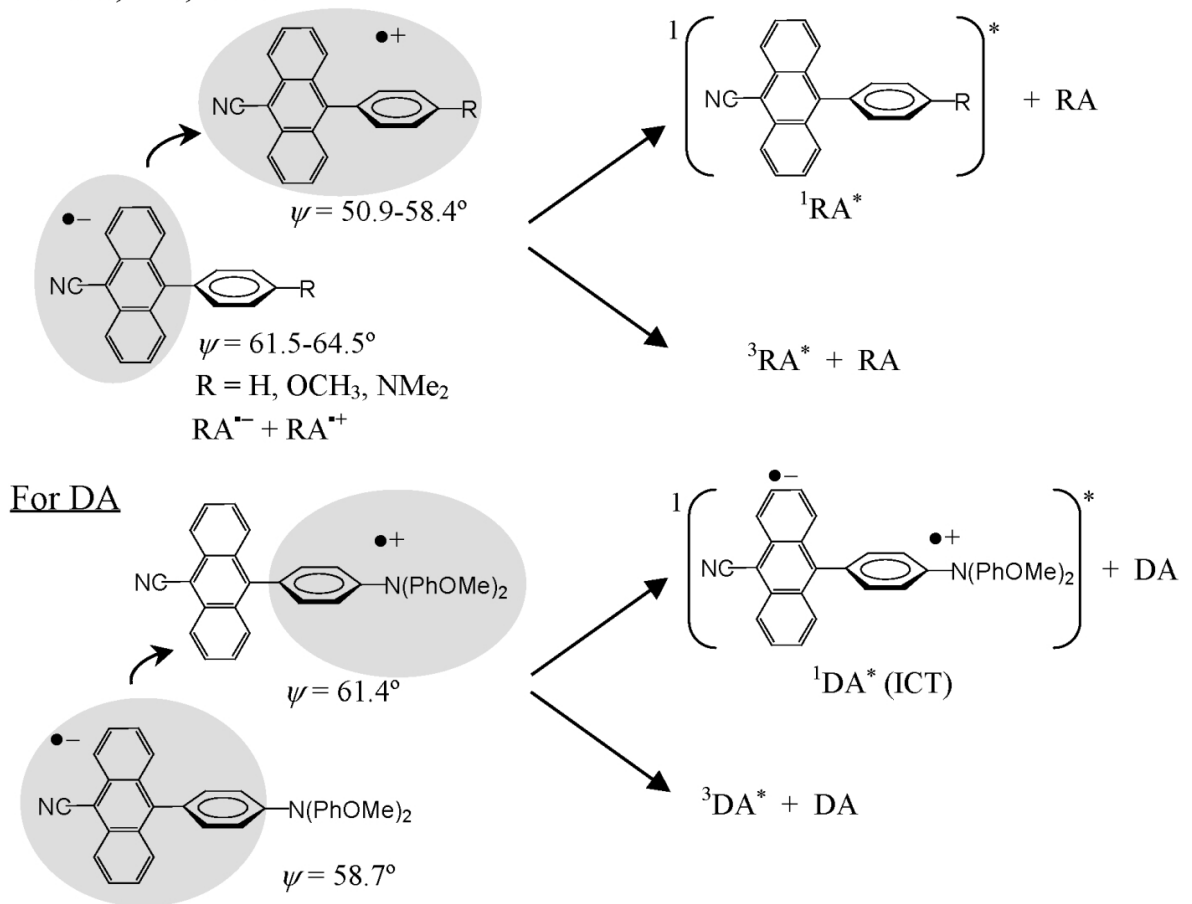

$\mathrm{DA}^{--}+\mathrm{DA}^{*+}$

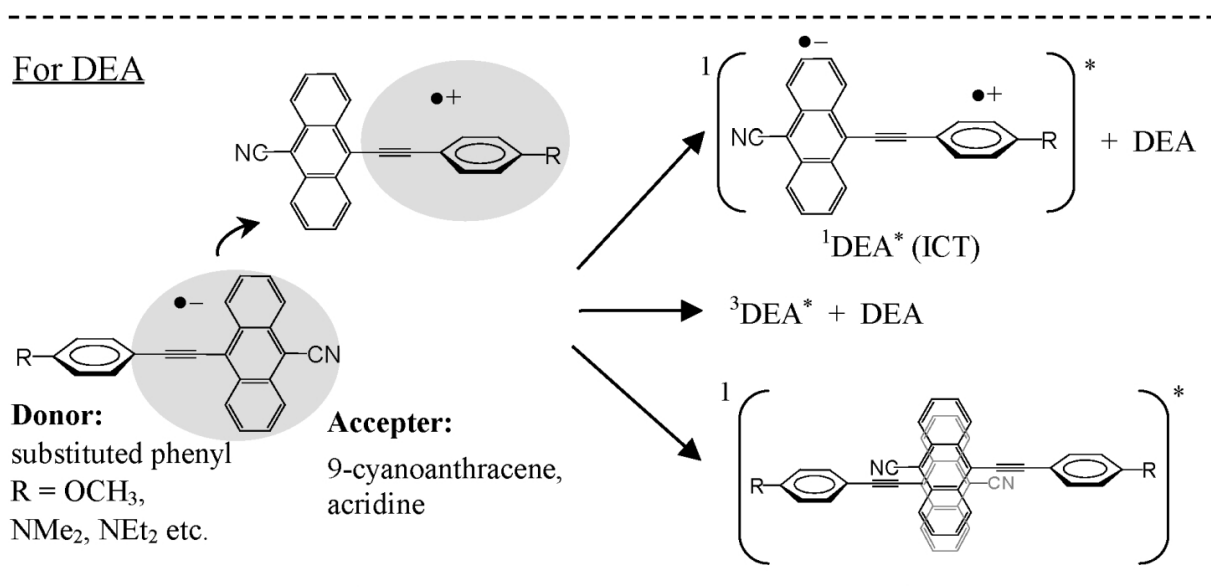

$\mathrm{DEA}^{*-}+\mathrm{DEA}^{*+}$

\section{CONCLUSIONS}

$\mathrm{RA}^{\bullet+}$ and $\mathrm{RA}^{\bullet-}$ generated during the pulse radiolysis of several substituted RA in various solvents were investigated with the focus on the emission between charge recombination of $\mathrm{RA}^{\cdot+}$ and $\mathrm{RA}^{--}$. When Bz was used as the solvent, RA showed the monomer emission during pulse radiolysis. The emission is suggested to be originated from ${ }^{1} \mathrm{RA}^{*}$ generated by the charge recombination between $\mathrm{RA}^{\circ+}$ and $\mathrm{RA}^{\circ-}$ which are generated from the initial radiolytic re- action in Bz. Based on the DFT (B3LYP/6-31G*) calculation, a twisted geometry was assumed for all RA. Therefore, it is expected that the charge recombination between $\mathrm{RA}^{\circ+}$ and $\mathrm{RA}^{\bullet-}$ does not give the excimer as the emissive species because of the twisted geometries of $\mathrm{RA}^{\bullet+}$ and $\mathrm{RA}^{\circ}$. The radiolysis induced emission intensity of RA is found not to be proportional to the $\phi_{\mathrm{fl}}$ value, suggesting that the energy difference between $-\Delta H^{\circ}$ and $E_{\mathrm{S} 1}\left(-\Delta H^{\circ}-E_{\mathrm{S} 1}\right)$ values is also an important factor for the emission efficiency. 


\section{ACKNOWLEDGEMENTS}

We thank the members of the Radiation Laboratory of SANKEN, Osaka University, for running the linear accelerator. This work has been partly supported by a Grant-in-Aid for Scientific Research (Project 17105005, Priority Area (417), $21^{\text {st }}$ Century COE Research, and others) from the Ministry of Education, Culture, Sports, Science and Technology (MEXT) of the Japanese Government.

Received July 7, 2006.

\section{REFERENCES}

1. (a) Goes, M.; Verhoeven, J. W.; Hofstraat, H.; Brunner, K. Chem. Phys. Chem. 2003, 4, 349. (b) Thomas, K. R. J.; Lin, J. T.; Tao, Y.-T.; Chuen, C.-H. Chem. Mater. 2002, 14, 3852. (c) Zhu, W.; Hu, M.; Yao, R.; Tian, H. J. Photochem. Photobiol., A 2003, 154, 169. (d) Thomas, K. R. J.; Lin, J. T.; Velusamy, M.; Tao, Y.-T.; Chuen, C.-H. Adv. Funct. Mater. 2004, 14, 83. (e) Chiang, C.-L.; Wu, M.-F.; Dai, D.-C.; Wen, Y.-S.; Wang, J.-K.; Chen, C.-T. Adv. Funct. Mater. 2005, 15, 231.

2. (a) Elangovan, A.; Chen, T.-Y.; Chen, C.-Y.; Ho, T.-I. Chem. Commun. 2003, 2146. (b) Elangovan, A.; Yang, S.-W.; Lin, J.-H.; Kao, K.-M.; Ho, T.-I. Org. Biomol. Chem. 2004, 2, 1597. (c) Elangovan, A.; Chiu, H.-H.;Yang, S.-W.; Ho, T.-I. Org. Biomol. Chem. 2004, 2, 3113. (d) Elangovan, A.; Kao, K.-M.; Yang, S.-W.; Chen, Y.-L.; Ho, T.-I.; Su, Y. O. J. Org. Chem. 2005, 70, 4460. (e) Yang, S.-W.; Elangovan, A.; Hwang, K.-C.; Ho, T.-I. J. Phys. Chem. B. 2005, 109, 16628.

3. Lin, J.-H.; Elangovan, A.; Ho, T.-I. J. Org. Chem. 2005, 70, 7397.

4. (a) Lai, R. Y.; Kong, X.; Jenekhe, S. A.; Bard, A. J. J. Am. Chem. Soc. 2003, 125, 12631. (b) Kapturkiewicz, A. Chem. Phys. 1992, 166, 259. (c) Kawai, M.; Itaya, K.; Toshima, S. J. Am. Chem. Soc. 1980, 84, 2368. (d) Lai, R. Y.; Fleming, J. J.; Merner, B. L.; Vermeij, R. J.; Bodwell, G. J.; Bard, A. J. J. Phys. Chem. A. 2004, 108, 376. (e) Strau $\beta$, J.; Daub, J. $A d v$. Mater. 2002, 14, 1652.

5. (a) Almenningen, A.; Bastiansen, O.; Fernholt, L.; Cyvin, B. N.; Cyvin, S. J.; Samdal, S. J. Mol. Struct. 1985, 128, 59. (b) Bastiansen, O.; Samdal, S. J. Mol. Struct. 1985, 128, 115.
6. (a) Buntinx, G.; Poizat, O. J. Chem. Phys. 1989, 91, 2153. (b) Sasaki, Y.; Hamaguchi, H. Spectrochim. Acta, Part A 1994, 50, 1475. (c) Rubio, M.; Merchan, M.; Orti, E.; Roos, B. O. J. Phys. Chem. 1995, 99, 14890. (d) Furuya, K.; Torii, H.; Furukawa, Y.; Tasumi, M. J. Mol. Struct. (THEOCHEM) 1998, 424, 225. (e) Arulmozhiraja, S.; Fujii, T.; Morita, M. J. Phys. Chem. A. 2002, 106, 10590. (f) Arulmozhiraja, S.; Fujii, T. J. Chem. Phys. 2001, 115, 10589.

7. (a) Pan, D.; Shoute, L. C. T.; Phillips, D. L. Chem. Phys. Lett. 2000, 316, 395. (b) Pan, D.; Phillips, D. L. Chem. Phys. Lett. 2000, 318, 214.

8. (a) Samori, S.; Hara, M.; Tojo, S.; Fujitsuka, M.; Yang, S.-W.; Elangovan, A.; Ho, T.-I.; Majima, T. J. Phys. Chem. B. 2005, 109, 11735. (b) Samori, S.; Tojo, S.; Fujitsuka, M.; Yang, S.-W.; Elangovan, A.; Ho, T.-I.; Majima, T. J. Org. Chem. 2005, 70, 6661. (c) Samori, S.; Tojo, S.; Fujitsuka, M.; Yang, S.-W.; Ho, T.-I.; Yang, J.-S.; Majima, T. J. Phys. Chem. B. 2006, 110, 13296.

9. (a) Scaiano, J. C. Handbook of Organic Photochemistry; CRC Press: Boca Raton, Florida, 1989; Vol. 1, p 231. (b) Reynolds, G. A.; Drexhage, K. H. Optics Commun. 1975, 13, 222.

10. (a) Baumann, W.; Schwager, B.; Detzer, N.; Okada, T.; Mataga, N. Bull. Chem. Soc. Jpn. 1987, 60, 4245. (b) Okada, T.; Kawai, M.; Ikemachi, T.; Mataga, N.; Sakata, Y.; Misumi, S.; Shionoya, S. J. Phys. Chem. A. 1984, 88, 1976.

11. Siemiarczuk, A.; Grabowski, Z. R.; Krówczyski, A.; Asher, M.; Ottolenghi, M. Chem. Phys. Lett. 1977, 51, 315.

12. (a) Lee, C.; Yang, W.; Parr, R. G. Phys. Rev. B 1988, 37, 785. (b) Beck, A. D. J. Chem. Phys. 1993, 98, 5648.

13. (a) Shida, T.; Hamill, W. H. J. Chem. Phys. 1966, 44, 2369 , 2375, 3472. (b) Shida, T.; Kato, T. Chem. Phys. Lett. 1979, 68, 106. (c) Grimison, A.; Simpson, G. A. J. Phys. Chem. 1968, 72, 1776. (d) Ishida, A.; Fukui, M.; Ogawa, H.; Tojo, S.; Majima, T.; Takamuku, S. J. Phys. Chem. 1995, 99, 10808. (e) Majima, T.; Tojo, S.; Ishida, A.; Takamuku, S. J. Org. Chem. 1996, 61, 7793. (f) Majima, T.; Tojo, S.; Ishida, A.; Takamuku, S. J. Phys. Chem. 1996, 100, 13615.

14. Shida, T. Electronic Absorption Spectra of Radical Ions; Physical Sciences Data 34; Elsevier Science Publishers: Amsterdam, 1988.

15. (a) Honda, E.; Tokuda, M.; Yoshida, H.; Ogasawara, M. Bull. Chem. Soc. Jpn. 1987, 60, 851. (b) Huddleston, R. K.; Miller, J. R. J. Phys. Chem. 1982, 86, 2410. (c) Majima, T.; Fukui, M.; Ishida, A.; Takamuku, S. J. Phys. Chem. 1996, 100, 8913. (d) Majima T.; Tojo, S.; Takamuku, S. J. Phys. Chem. A 1997, 101, 1048. 